American Journal of Physics and Applications
2021; 9(1): $25-28$
http://www.sciencepublishinggroup.com/j/ajpa
doi: 10.11648 /j.ajpa.20210901.14
ISSN: 2330-4286 (Print); ISSN: $2330-4308$ (Online)

\title{
A GSM Based Intelligent Solar Energy Measuring System
}

\author{
Salami Olugbenga, Green Oluwole \\ Department of Computer Engineering, Lagos State Polytechnic, Ikorodu, Nigeria \\ Email address: \\ solad_33@yahoo.com (S. Olugbenga),oluwolegreen@gmail.com (G. Oluwole)
}

\section{To cite this article:}

Salami Olugbenga, Green Oluwole. A GSM Based Intelligent Solar Energy Measuring System. American Journal of Physics and Applications. Vol. 9, No. 1, 2021, pp. 25-28. doi: 10.11648/j.ajpa.20210901.14

Received: January 6, 2021; Accepted: February 14, 2021; Published: March 17, 2021

\begin{abstract}
A Photovoltaic (PV) power monitoring is important in PV systems for proper generation and transmission. With the need to monitor certain parameters like voltage, current and power in order to ascertain the power output of a solar system. In this project design, a GSM solar power monitoring system is designed in order to monitor the voltage, current and output power of a solar system and also transmit the monitored parameters in real time to a remote location via the SMS feature of the GSM technology. An 8 bit 18F452 PIC microcontroller is used as the control unit which controls the Pulse width Modulation (PWM) solar charge controller, IRF3205 MOSFETs as the switching transistors in the charge controller charging a $30 \mathrm{AH} 12 \mathrm{v}$ battery via a 30watts polycrystalline solar panel. Universal asynchronous synchronous receiver and transmitter (USART) is used as protocol for transmission between a Sim 900 GSM module and the microcontroller while the attention (AT) command is used as the communication protocol in sending measured power parameters from the microcontroller to the GSM module which in turn sends the measured parameters as SMS message to a remote location. ACS 712 hall effect current sensor for measuring current and a voltage divider network for measuring the PV cell voltage. The circuit board is printed on a Printed circuit board (PCB) using the traditional transfer method. C programming language is used in writing program codes embedded on the controller. This project design have been able to show that by employing the use of a wireless real time data monitoring (GSM technology), PV systems can be properly monitored remotely for consumption, operation, analysis and isolation in cases of fault detection.
\end{abstract}

Keywords: Photovoltaic, Modulation, MOSFET, Communication

\section{Background Study}

Power is an important aspect of human life, over the years humans have been able to find better ways of making life easier and stress free for themselves. From the discovery of fire, from the using of striking stones together to the era of burning coals to power devices and instruments to the discovery of renewable form of power source. It can be concluded that the need of power will always be important no matter the source.

The solar radiation that reaches the surface of the earth without being diffused is called direct beam solar radiation. It is measured by instrument called pyranometer. As sun light passes through the atmosphere, some part of it is absorbed, scattered and reflected by air molecule, water vapours, clouds, dust and pollutants. This is called diffuse solar radiation. The diffuse solar radiation does not have unique path. The sum of the direct and diffuse solar radiations is called total radiation. Pyranometer is used for measuring the total radiation. Therefore, we are considering how to measure the beam solar radiation as a source of power supply. Furthermore, our project talks about how energy is been gotten or trapped from the sun, methods, measurement of power parameter, mode of operation, result and the usefulness of the solar energy. With a GSM model incorporated in the system, real time information can be obtained from the system via short message service (SMS) communication. Thus remote monitoring is essential. For developing remote monitoring system for solar photovoltaic unit, GSM wireless transmission approach is taken in this work which actually envisions a near future where everyday objects will be armed with microcontrollers and transceivers for digital communication. The remote monitoring eliminate the hazards associated with the traditional wiring systems and make data measurement and monitoring process much easier and cost effective and GSM based systems take a giant leap towards monitoring by intelligent decision making from a central system. The decentralized architecture of the remote monitoring systems and its flexibility of deployment make it 
most suitable for domestic and small-scale purposes [12].

Presently, solar photovoltaic (PV) energy is one of the major renewable energy sources due to its availability in SubSaharan Africa. Africa is often considered as the 'Sun Continent' as Africa receives many more hours of bright sunshine during the course of the year than any other continent of the Earth [9]. In Nigeria, renewable energy penetration is still in its nascent stage, the only source of renewable energy in the country is hydropower. Wind and solar energy have only been deployed in a minuscule amount. With energy policies and initiatives developing, wind and solar energy generation projects are gradually being planned throughout the country. As local monitoring is not convenient for the installer therefore monitoring remotely is essential for every solar power plant. Hence, the use of GSM technology for monitoring solar power plants is a promising approach [10].

Adhya et al., proposed an IOT based remote monitoring system for solar power plant, designed a system using a 16 bit PIC microcontroller, passing data through GPRS and Internet of Things (IOT) [13].

In a related work, Shariff et al., carried out a study on photovoltaic remote monitoring, a hardware and data acquisition devices is was built using sensors, microcontroller, RTC and LCD. The sensitivity of the voltage sensor used, ranges from 0 to $100 \mathrm{~V}$ while current sensor ranges from 0 to $25 \mathrm{~A}$, making the voltage and current sensors deployed as one of the highest ever deployed in a PV system project. Sheriff etal also deployed a 16 bits PIC18F4550 microcontroller which support more than five analog to digital converter channel (ADC) $[1,4]$.

In close proximity to Sheriff work, $\mathrm{S}$. Dalcento opined that the overall performance of a PV system dependes on the performance of each subsystem, and the classification of monitoring and diagnosis (M\&D) of PV system is based on the level of granularity (LoG) in which only the instantaneous output power generated by the PV field, at either the $\mathrm{DC}$ or $\mathrm{AC}$ side is measured and converted into energy yield of plant [14].

Also, some research work on Photovotaic cell proposed a system using microcontroller \& IOT to produce a system, smart enough to make suggestions if the panel is not working properly, it was made to detect any theft or malfunction and to optimize energy production by efficient algorithm using ephemeral table stored in the system to derive the plant's solar tracking $[5,7]$.

Similarly, Sánchez-Pacheco et al., (2014) used a PLC communication technology on a dc lines to achieve a real time monitoring of a PV system, reducing the general cost of transmission and installations of a solar panel system [3].

Soteris etal established that Artificial Intelligence techniques have been used by various researchers in solar energy application. Various researchers have through AI application predicts solar radiation and energy consumption of a passive solar buildings. [15]

Also using artificial intelligence, Paras Mendel etal uses AI application to forecast the solar PV power. He proposed hybrid method for hourly forecasting of solar PV power based on the combination of Neural Network (NN) and Wavelet Transform (WT) to minimize the number of input data, while maximizing the accuracy of the proposed combined approach. [8]

The previous works done on the GSM based intelligent solar energy measurement system are all having a similar means of collecting information from the solar system, which are limited by distance, but this proposed project is a two ways means of getting information from the solar system. This makes it more efficient and effective, with the use of GSM module, which enable us to get information remotely and over very long distance [3].

\section{System Design and Implementation}

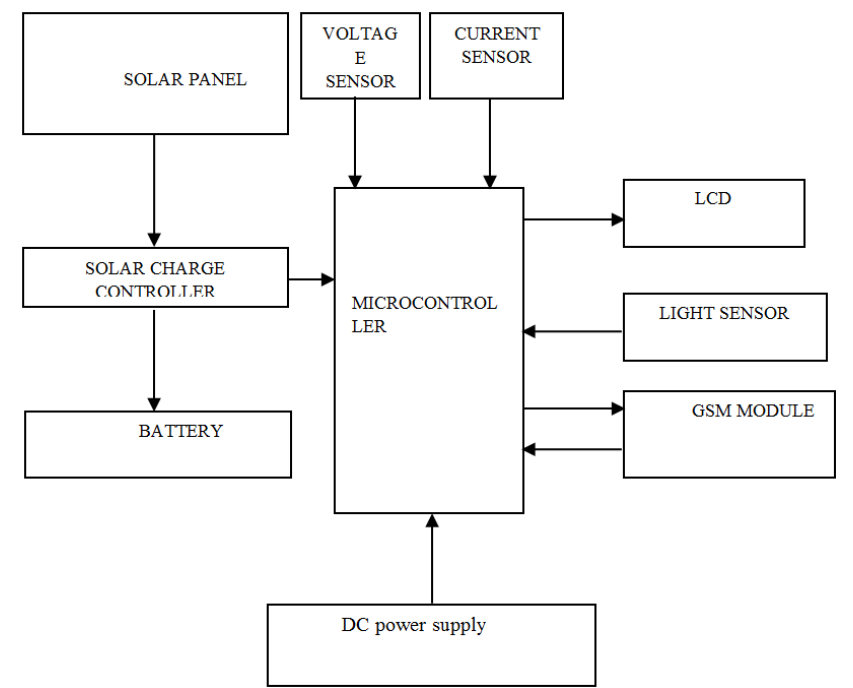

Figure 1. Block diagram of the GSM base intelligent solar energy measuring system.

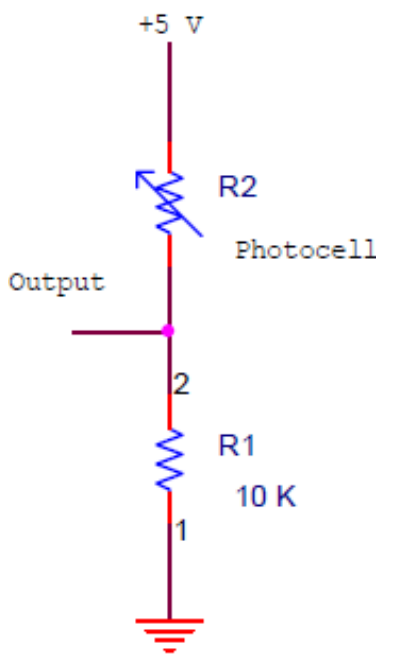

Figure 2. CDS photocell circuit.

The control unit which is the major control layer of the solar energy measuring system as contained in figure 1 , is made up of PIC18F452 microcontroller which coordinates the operations of all the elements in the system by taking 
analog input readings from the current and voltage sensors, and convert them into digital readings which is displayed on the LCD. A calculated power, which is the processed results of the inputs gathered by the microcontroller is later sent remotely through the GSM modules to the end user who keeps the data to monitor the measuring process.

The photocell used in this project is the Cadmium Sulfide (CDS) photocell. CDS is a passive component whose resistance is inversely proportional to the amount of light intensity directed towards it $[2,6]$. Meaning that the output impedance of a photocell tends to infinity at dark condition, with zero output voltage, and during the bright light, the output impedance drops to few ohms with output voltage at maximum. For effective result, the photocell is connected in series with a regulating resistor, forming a voltage divider $[11,16]$. The output of the photocell is tapped from the regulating resistor as depicts in figure 2 giving the output in the detailed calculation below;

$$
\text { Vout }=\left(\frac{R 1}{R 1+R 2}\right) V C C
$$

$\mathrm{R} 2=$ Photocell varying resistance value at varying light conditions

$\mathrm{R} 1=10 \mathrm{k}$

$\mathrm{VCC}=5 \mathrm{v}$

At dark condition:

$$
\text { Vout }=\left(\frac{10000}{10000+990000}\right) * 5
$$

Vout $=0.005 \mathrm{v}$

Likewise, at bright light condition:

$$
\text { Vout }=\left(\frac{10000}{10000+408}\right) * 5
$$

Vout $=4.804 \mathrm{v}$

The result of the photocell condition of operation is shown in table 1.

Table 1. Photocell condition of Operation.

\begin{tabular}{lll}
\hline Condition & Voltage & Resistance \\
\hline Dark condition & $0.05 \mathrm{v}$ & $990 \mathrm{kOhms}$ \\
Average & $2.65 \mathrm{v}$ & $8.84 \mathrm{kOhms}$ \\
Bright light & $4.8 \mathrm{v}$ & $408 \mathrm{Ohms}$ \\
\hline
\end{tabular}

\section{Testing and Result}

The construction of the GSM based intelligent solar energy measurement system passed through the different construction stage, before it's finally design, during these stages several test were performed. The project was first designed on a bread board which was the hardware construction stage and designed on a simulation software to get the actual result been displayed before the finally design on a printed circuit board.

During the implementation of the project different test were performed, such as test for continuity, which involve the use of multi-meter to test for the flow and direction of current in the circuit. In our case a digital multi-meter was used in order to get the appropriate value of the necessary voltages on the circuit. Another test that was carried out was the test for error during programming of the microcontroller to make sure the source code will properly run and error free. This process is called DEBUGGING.

Various test result of solar energy measurement and microcontroller initiated codes are drawn in tables 2 and 3 respectively.

Table 2. SOLAR Monitoring unit.

\begin{tabular}{lll}
\hline Output Current & Output Voltage & Power \\
\hline $2.5 \mathrm{~A}$ & $18 \mathrm{v}$ & $45 \mathrm{~W}($ Peak Sunlight-1 $\mathrm{pm})$ \\
$2 \mathrm{~A}$ & $12 \mathrm{v}$ & $24 \mathrm{~W}$ (ModerateSun-3:30pm) \\
$1.5 \mathrm{~A}$ & $8 \mathrm{v}$ & $12 \mathrm{~W}$ (Low Sun) \\
\hline
\end{tabular}

Table 3. Output voltage on TX pin (Pin 15).

\begin{tabular}{lll}
\hline Output Voltage & Output Current & Status \\
\hline $4.2 \mathrm{v}$ & $200 \mathrm{~mA}$ & SMS SENT \\
$0.2 \mathrm{v}$ & $0 \mathrm{~A}$ & NO SMS SENT \\
\hline
\end{tabular}

The program codes prompt the MCU to send SMS at a specific interval of time.

\section{Conclusion}

Renewable power generation is very important in our world to ensure the smooth running of various human activities and also to improve standard of living e.g. homes, industries etc. Power generating methods can be automated by creating a system that will be able to measure or monitor it. This system is referred to as an intelligent measuring or monitoring system.

This project work presents a GSM based intelligent solar energy power monitoring system which is able to monitor solar power and parameters remotely to help increase power generation in the world today. The system is a microcontroller based system which specifically demonstrates a working software solution for effective alternative power generation scheduling in order to optimize solar power generated effectively. The system also has other features such as light intensity sensing, voltage sensing, current sensing and a microcontroller power point charger.

\section{References}

[1] Amin, N., Yi, L. Z., \& Sopian, K. (2009, June). Microcontroller based smart charge controller for standalone solar photovoltaic power systems. In Photovoltaic Specialists Conference (PVSC), 2009 34th IEEE (pp. 001094-001097). IEEE.

[2] Boylestad, R. L., Nashelsky, L., \& Li, L. (2002). Electronic devices and circuit theory (Vol. 11). Englewood Cliffs, NJ: Prentice Hall.

[3] F. J. S'anchez-Pacheco, P. J. Sotorr'10-Ruiz, J. R. HerediaLarrubia, F. P'erez-Hidalgo, and M. S. De Cardona (2014), "PLC-based PV plants smart monitoring system: field measurements and uncertainty estimation," IEEE Transactions on Instrumentation and Measurement, vol. 63, no. 9, pp. 2215-2222. 
[4] F. Shariff, N. A. Rahim, and H. W. Ping (2013), "Photovoltaic remote monitoring system based on GSM," in Proceedings of the IEEE Conference onClean Energy and Technology (CEAT '13), pp. 379-383.

[5] H. S Nalamwar et al (2017). Automated Intelligent Monitoring and the Controlling software system for solar panels: Journals of Physics conference series.

[6] Lander, C. W. (1999). Power Electronics, Second Edition, S Chand \& Company.

[7] P. Visconti \& G. Cavalera (2015). Intelligent system for monitoring and control of photovoltaic plants and for optimization of solar energy production: International Conference on Environmental and Electrical Engineering.

[8] Paras Mendel, Suriya Teja, Swaroop Madhiva, Ashraf UI Hague, Julian Meng, Relardo Pineda (2012), forecasting power output of solar photovoltaic system using wavelet transform and artificial intelligence techniques. Conference of Missouri University of Science and Technology, Washington DC.

[9] Powell, R, Bowdeen D, Tresemer D, Bento W, Farrants W, Gray B, Damn K, Paul L, Lainson C. M. L, Nurmey S (2012). Journal of start wisdom.

[10] Rahman, M. M., Islam, M. O., \&Salakin, M. S. (2015).
Arduino and GSM based smart energy meter for advanced metering and billing system. In Electrical Engineering and Information Communication Technology (ICEEICT), 2015 International Conference on (pp. 1-6). IEEE.

[11] Rashid, M. H. (2009). Power electronics: circuits, devices, and applications. Pearson Education India.

[12] Rusydi, M. I., Putra, R., \& Putra, M. H. (2016, October). Realtime measurement of grid connected solar panels based on wireless sensors network. In Sustainable Energy Engineering and Application (ICSEEA), 2016 International Conference on (pp. 95-99). IEEE.

[13] S. Adhya1, D. Saha, A. Das, J. Jana, H. Saha, an IoT based smart solar photovoltaic remote monitoring and Control unit, 2nd International Conference on Control, Instrumentation, Energy \& Communication (CIEC).

[14] S. Dalcento (2017). Monitoring, Diagnosis and Power forecasting for photovoltaic fields: a review: Hindawi International Journal of Photoenergy.

[15] Soteris A. Kalogirous \& Arzu Sencan (2010), artificial intelligence techniques in solar energy applications. www.researchgate.net. Retrieved on 23/1/2021.

[16] Theraja, A. K. (1999). A Text Book of Electrical Technology ( $5^{\text {th }}$ ed.). 